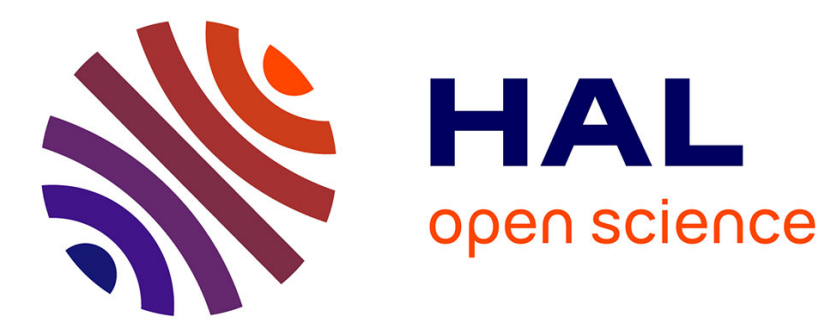

\title{
Coupling between the frequency droop and the voltage droop of an AC/DC converter in an MTDC system
}

\author{
Samy Akkari, Jing Dai, Marc Petit, Xavier Guillaud
}

\section{To cite this version:}

Samy Akkari, Jing Dai, Marc Petit, Xavier Guillaud. Coupling between the frequency droop and the voltage droop of an AC/DC converter in an MTDC system. PowerTech, 2015 IEEE Eindhoven, Jun 2015, Eindhoven, France. 10.1109/PTC.2015.7232285 . hal-01244005

\section{HAL Id: hal-01244005 \\ https://hal-centralesupelec.archives-ouvertes.fr/hal-01244005}

Submitted on 15 Dec 2015

HAL is a multi-disciplinary open access archive for the deposit and dissemination of scientific research documents, whether they are published or not. The documents may come from teaching and research institutions in France or abroad, or from public or private research centers.
L'archive ouverte pluridisciplinaire HAL, est destinée au dépôt et à la diffusion de documents scientifiques de niveau recherche, publiés ou non, émanant des établissements d'enseignement et de recherche français ou étrangers, des laboratoires publics ou privés. 


\section{Coupling between the Frequency Droop and the Voltage Droop of an AC/DC Converter in an MTDC System}

\author{
S. Akkari, J. Dai, M. Petit \\ Group of Electrical Engineering Paris (GeePs), \\ CentraleSupélec, CNRS UMR 8507, UPSud and UPMC \\ Gif-sur-Yvette, France \\ samy.akkari@centralesupelec.fr
}

\author{
X. Guillaud \\ Laboratory of Electrical Engineering \\ and Power Electronics (L2EP Lille), \\ École Centrale of Lille \\ Lille, France
}

\begin{abstract}
MTDC systems are required to be reliable, and in certain cases, should participate in the $\mathrm{AC}$ grids frequency regulation. This can be achieved by providing AC/DC converters with a dual controller combining both the voltage-droop and the frequency-droop control techniques. In this paper, the coupling between the two droops is theoretically investigated and quantified for both a DC side fault and an AC side fault. A 5-terminal HVDC grid is simulated to validate the theoretical results.
\end{abstract} trol.

Index Terms-frequency control, HVDC, MTDC, voltage con-

\section{INTRODUCTION}

It is anticipated that the North Sea will hold an installed wind energy capacity of more than $100 \mathrm{GW}$ by 2030 [1], [2]. The Multi-Terminal HVDC (MTDC) technology seems to be the most feasible solution to connecting the wind farms to onshore grids as well as interconnecting asynchronous AC systems [3]. Over the last decade, voltage-droop-based control schemes have become the preferred option to safely and reliably coordinate the power exchange between the terminals [4], [5].

With the shut-down of polluting conventional generation units participating in the frequency regulation, MTDC systems will most likely be solicited to support the AC grids' frequency. This can be achieved through the power electronics of the converters by using a frequency-droop controller [6], [7], based on the same principle as the speed governor used in conventional generation units in $\mathrm{AC}$ grids.

Ideally, any converter connected to an onshore AC grid should be equipped with a dual controller implementing both droops. However, [8] shows that using both droops at the same time leads to interactions between the AC grids and the MTDC system that degrade the efficiency of each droop. These interactions need to be theoretically quantified and the frequency droop parameter must be corrected so that the frequency droop still fulfils the agreement with the TSO despite the coupling between the two droops. The impact of these interactions on the DC voltage variations also needs to be quantified in order to allow the correct design of the DC voltage-droop parameters as well as the DC grid.

\section{The Dual Control Technique}

\section{A. Control of the VSC-HVDC converter}

The modelling and the control of the VSC-HVDC converter has already been covered in the literature (see [5] and [9]). One common model is depicted in Figure 1, where two droops modify the power reference of the active power loop of the converter.

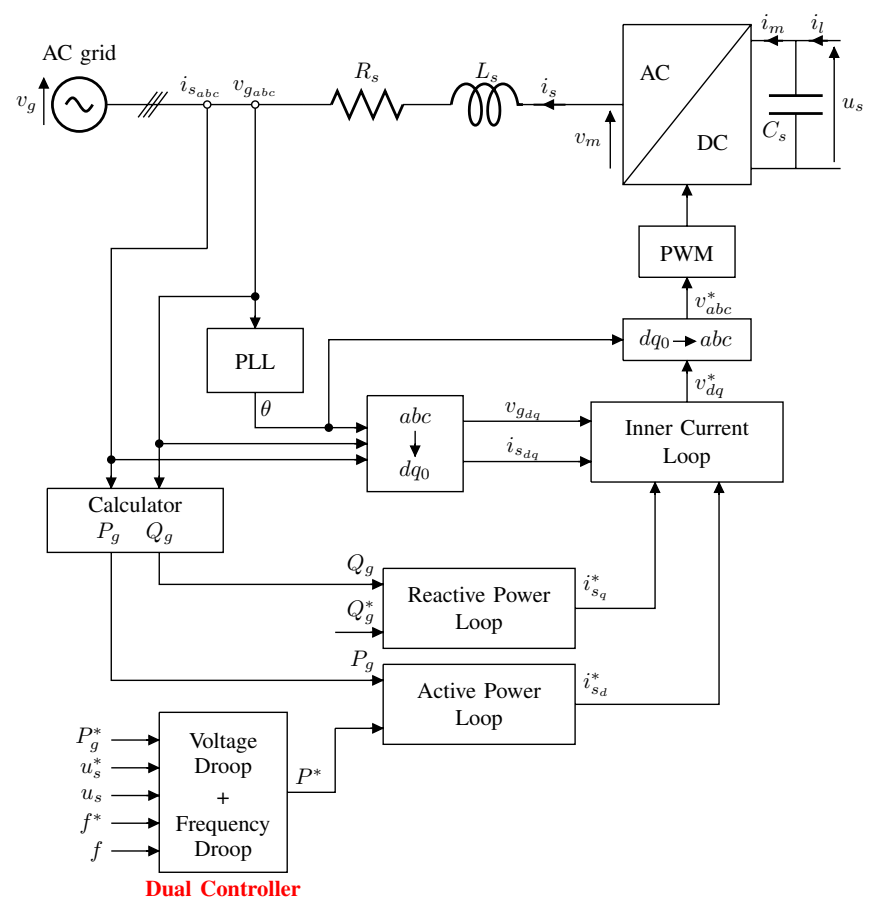

Fig. 1. Control strategy of a VSC-HVDC converter

\section{B. The dual control technique}

The functioning of the voltage droop and the frequency droop is fully detailed in [8]. The combination of the 
frequency-droop and the voltage-droop control techniques leads to a dual controller depicted in Figure 2. This dual controller enjoys the advantages of the two droops. However, their combination also leads to undesirable side-effects which will be further discussed in the following section.

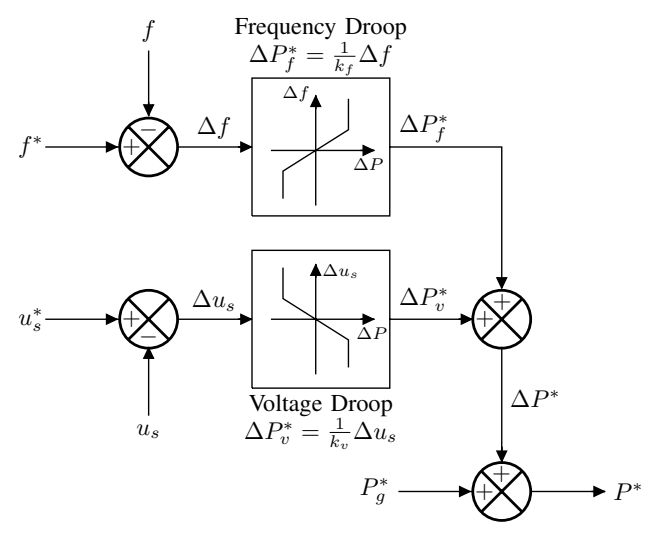

Fig. 2. Working principle of the dual controller

With this dual controller, the $i^{\text {th }}$ converter's operating point obeys

$$
\begin{aligned}
\Delta P_{i}^{*} & =\Delta P_{v_{i}}^{*}+\Delta P_{f_{i}}^{*} \\
& =\frac{1}{k_{v_{i}}} \Delta u_{s_{i}}+\frac{1}{k_{f_{i}}} \Delta f_{i}
\end{aligned}
$$

where:

- $\Delta P_{i}^{*}$ is the total power reference deviation of the $i^{\text {th }}$ VSC-HVDC converter. A positive $P_{i}$ corresponds to a power injection from the DC grid to the $\mathrm{AC}$ grid.

- $k_{v_{i}}$ is the voltage-droop parameter of the $i^{\text {th }}$ converter, $k_{v_{i}}<0$.

- $\Delta u_{s_{i}}$ is the DC voltage control error at the $i^{\text {th }}$ converter terminal with regard to its voltage reference: $\Delta u_{s_{i}}=$ $u_{s_{i_{\text {ref }}}}-u_{s_{i}}$.

- $k_{f_{i}}$ is the frequency-droop parameter of the $i^{\text {th }}$ converter, $k_{f_{i}}>0$.

- $\Delta f_{i}$ is the frequency control error of the AC grid connected to the $i^{\text {th }}$ converter with regard to its frequency reference: $\Delta f_{i}=f_{i_{\text {ref }}}-f_{i}$.

\section{The dual nature of the controller}

Using both droops at the same time creates a coupling between them. In fact, if the DC voltage decreases, the voltage droop modifies the power operating point of the converter to retain more energy inside the DC grid. As a consequence, the balancing is modified in the AC areas. The frequency droop is then activated and opposes the action of the voltage droop by re-modifying the power operating point in the opposite direction in order to inject more power into the $\mathrm{AC}$ grids.

This coupling is problematic since it degrades the performances of both droops. However, when the AC grid needs frequency support, priority should be given to the frequency droop since the TSO of the concerned AC grid expects that the VSC-HVDC converter should respect a contractual value of the frequency droop. Thus, the impact of the voltage droop on the frequency droop must be corrected in order to comply with the TSO's requirements. On the other hand, the impact of the frequency droop on the voltage droop in the event of a DC fault also needs to be quantified in order to choose the voltage-droop parameter correctly.

\section{Theoretical Study on the Mutual Impact of Two DROOPS}

\section{A. Impact of the voltage droop on the functioning of the frequency droop}

In this section, the impact of the voltage droop on the frequency droop in the event of an AC fault is studied.

This theoretical study tries to find the relation between the frequency deviation of the $\mathrm{AC}$ grid and the effective power deviation of the converter connected to the $\mathrm{AC}$ grid under the dual controller. It is assumed each $\mathrm{AC}$ grid is connected to the DC grid through a single VSC converter.

In order to simplify the equations, the following simplifying assumption is made:

DC voltage variations are identical at all nodes of the HVDC grid. This is equivalent to neglecting the variation of the power losses in the DC grid.

Hence, for an MTDC system with $n$ converters:

$$
\forall j \in\{1, \ldots, n\}, \quad \Delta u_{s_{j}}=\Delta u_{s}
$$

After an AC event such as the loss of a generation unit or a load change, the effective power deviation of each one of the $n$ converters obeys its reference described by (1), which gives

$$
\forall j \in\{1, \ldots, n\}, \quad \Delta P_{j}=\frac{1}{k_{v_{j}}} \Delta u_{s}+\frac{1}{k_{f_{j}}} \Delta f_{j}
$$

If the considered converter $j$ is not equipped with a voltagedroop and/or a frequency-droop controller then $k_{v_{j}}=-\infty$ and/or $k_{f_{j}}=\infty$.

The sum of the $n$ equations (3) gives:

$$
\sum_{j=1}^{n} \Delta P_{j}=\sum_{j=1}^{n} \frac{1}{k_{v_{j}}} \Delta u_{s}+\sum_{j=1}^{n} \frac{1}{k_{f_{j}}} \Delta f_{j}
$$

Since the variation of the power losses is neglected and that the power on the DC grid is balanced by the converters equipped with a voltage droop, we have $\sum_{j=1}^{n} \Delta P_{j}=0$.

Thus (4) becomes:

$$
\sum_{j=1}^{n} \frac{1}{k_{v_{j}}} \Delta u_{s}=-\sum_{j=1}^{n} \frac{1}{k_{f_{j}}} \Delta f_{j}
$$

In addition, since $\Delta u_{s}$ is considered identical for all VSCHVDC converters, (5) leads to a new expression of $\Delta u_{s}$ :

$$
\Delta u_{s}=\frac{-1}{\sum_{j=1}^{n} \frac{1}{k_{v_{j}}}} \sum_{j=1}^{n} \frac{1}{k_{f_{j}}} \Delta f_{j}
$$


Let us now consider the $i^{\text {th }}$ converter of the MTDC system. Replacing $\Delta u_{s}$ in (3) by (6) yields:

$$
\Delta P_{i}=\frac{-1}{k_{v_{i}} \sum_{j=1}^{n} \frac{1}{k_{v_{j}}}}\left(\sum_{j=1}^{n} \frac{1}{k_{f_{j}}} \Delta f_{j}\right)+\frac{1}{k_{f_{i}}} \Delta f_{i}
$$

Equation (7) shows that the power deviation of the $i^{\text {th }}$ converter consists of:

$\triangleright$ The power deviation created by the sum of the frequency droops of every converter on the DC grid weighted by $\frac{-1}{k_{v_{i}} \sum_{j=1}^{n} \frac{1}{k_{v_{j}}}}$. This coefficient depends on the contribution of each converter participating in the DC voltage regulation of the DC grid (voltage-droop parameters $k_{v_{j}}$ ).

$\triangleright$ The power deviation created by the frequency droop of the $i^{\text {th }}$ converter.

Since the maximum power deviation of an AC/DC converter is limited and that the total power transmitted through a converter is usually small compared to the $\mathrm{AC}$ grid total active power, then if there is no $\mathrm{AC}$ fault occurring at the same time on the other $\mathrm{AC}$ grids, $\Delta f_{j}$ for $j \neq i$ are negligible and (7) becomes:

$$
\Delta P_{i}=\frac{1}{k_{f_{i}}}\left(1-\frac{1}{k_{v_{i}} \sum_{j=1}^{n} \frac{1}{k_{v_{j}}}}\right) \Delta f_{i}
$$

Hence, because of the interaction between the frequency droop and the voltage droop, the actual relation between the AC grid frequency and the converter connected to this grid is now described by (8). This means the effective frequency-droop value, $k_{f_{i}}^{\prime}$ (ratio of the frequency and the power extracted or withdrawn from the AC grid), is not equal to the initial frequencydroop value $k_{f_{i}}$ since $k_{f_{i}}^{\prime}=\frac{\Delta f_{i}}{\Delta P_{i}}=\frac{k_{f_{i}}}{\left(1-\frac{1}{k_{v_{i}} \sum_{j=1}^{n} \frac{1}{k_{v_{j}}}}\right)}$.

In order for the effective frequency droop to satisfy the contractual frequency-droop value $k_{f_{i_{\text {contractual }}}}$ required by the TSO, the initial frequency-droop parameter $k_{f_{i}}$ must be corrected such that the corrected value takes into account the voltage-droop parameter of each converter of the DC grid:

$$
k_{f_{i}}=k_{f_{i_{\text {contractual }}}}\left(1-\frac{1}{k_{v_{i}} \sum_{j=1}^{n} \frac{1}{k_{v_{j}}}}\right)
$$

In this case, the effective frequency-droop value $\left(k_{f_{i}}^{\prime}\right)$ is actually equal to the contractual frequency-droop value $\left(k_{f_{i_{\text {contractual }}}}\right)$ agreed with the TSO.

\section{B. Impact of the frequency droop on the functioning of the voltage droop}

In this section, the impact of the frequency droop on the voltage droop in the event of a DC fault is studied.

Even though priority should be given to the frequency droop for AC grid support, the voltage droop is important for regulating the voltage of the DC grid, especially when a DC fault occurs. In fact, a malfunctioning of the voltage droop could cause the whole MTDC system to collapse in the event of a DC fault.

Since a DC fault can lead to a converter loss, this study considers that $n-1$ converters are still connected to the DC grid after a DC fault while the $k^{\text {th }}$ converter is lost. The power deviation of each converter after the DC fault is as follows:

$$
\left\{\begin{array}{l}
\forall j \in\{1, \ldots, n\} \backslash\{k\}, \Delta P_{j}=\frac{1}{k_{v_{j}}} \Delta u_{s}+\frac{1}{k_{f_{j}}} \Delta f_{j} \\
\Delta P_{k}=\Delta P_{\text {fault }_{k}}=-P_{k}
\end{array}\right.
$$

The sum of the $n-1$ equations (10) gives:

$$
\sum_{\substack{j=1 \\ j \neq k}}^{n} \Delta P_{j}=\sum_{\substack{j=1 \\ j \neq k}}^{n} \frac{1}{k_{v_{j}}} \Delta u_{s}+\sum_{\substack{j=1 \\ j \neq k}}^{n} \frac{1}{k_{f_{j}}} \Delta f_{j}
$$

Since the variation of the power losses is neglected and that the power on the DC grid is balanced by the converters equipped with a voltage droop, $\sum_{\substack{j=1 \\ j \neq k}}^{n} \Delta P_{j}=P_{k}$.

Thus (11) becomes:

$$
\sum_{\substack{j=1 \\ j \neq k}}^{n} \frac{1}{k_{v_{j}}} \Delta u_{s}=P_{k}-\sum_{\substack{j=1 \\ j \neq k}}^{n} \frac{1}{k_{f_{j}}} \Delta f_{j}
$$

In addition, since the DC voltage deviations are supposed identical for all VSC-HVDC converters, (12) leads to a new expression of $\Delta u_{s}$ :

$$
\Delta u_{s}=\frac{1}{\sum_{\substack{j=1 \\ j \neq k}}^{n} \frac{1}{k_{v_{j}}}}\left(P_{k}-\sum_{\substack{j=1 \\ j \neq k}}^{n} \frac{1}{k_{f_{j}}} \Delta f_{j}\right)
$$

Equation (13) shows that the DC voltage variation of the HVDC grid consists of the difference of the power initially injected or withdrawn by the lost converter and the power deviation created by the sum of the frequency droops of every converter on the DC grid. This difference is weighted by the coefficient $\frac{1}{\sum_{\substack{j=1 \\ j \neq k}}^{n} \frac{1}{k_{v_{j}}}}$ which depends on the contribution of each converter still connected to the DC grid after the disturbance and participating in the DC voltage regulation (voltage-droop parameters $k_{v_{j}}$ ).

\section{Case Study}

This section illustrates the behaviour of a 5-terminal MTDC system interconnecting two offshore wind farms and three asynchronous AC grids.

The AC grid 1 is either strong (such as a continental AC grid) or weak (such as an islanded AC grid) depending on the simulations, whereas AC grids 2 and 3 are always strong $\mathrm{AC}$ grids. Converters 1, 2 and 3 are equipped with dual controllers (frequency and voltage droops) whereas converters 4 and 5 do not have the dual controller since they are connected to offshore wind-farms and inject all the power harvested by the wind-farms into the DC grid. Since the time lapse of this study is about 20 seconds only, the power output of the wind farms are supposed constant. 
Simulations are run using EMTP-RV. The 5-terminal HVDC grid topology is depicted in Figure 3. The topology of the AC grid 1 with 5 generators used in these simulations as well as the AC and DC line parameters are detailed in the Appendix.

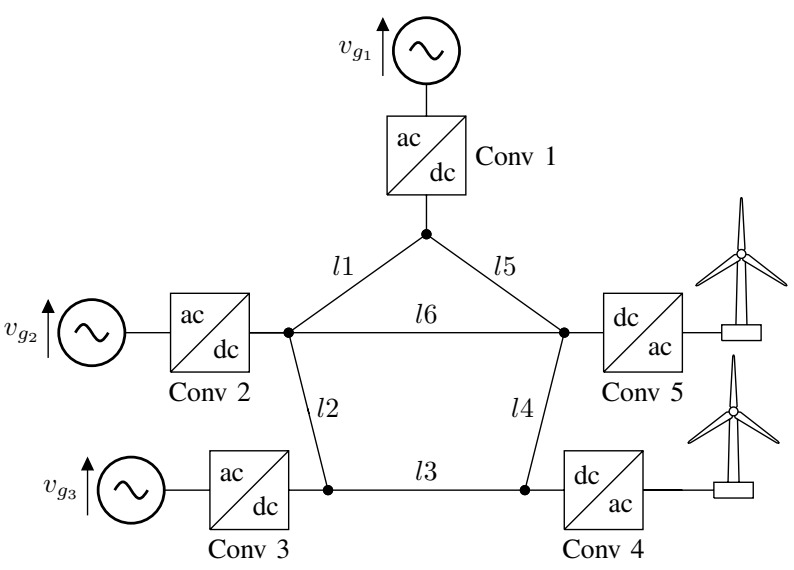

Fig. 3. Topology of the HVDC grid

The initial power reference of each VSC-HVDC converter as well as their droop coefficients ${ }^{1}$ are shown in Table I.

\begin{tabular}{|c|c|c|c|c|c|}
\hline Converter & $\mathbf{1}$ & $\mathbf{2}$ & $\mathbf{3}$ & $\mathbf{4}$ & $\mathbf{5}$ \\
\hline$P_{g}^{*}$ (MW) & 200 & 200 & -50 & -162 & -200 \\
\hline$k_{v}$ (p.u.) & -0.4834 & -0.4834 & -0.4834 & $-\infty$ & $-\infty$ \\
\hline$k_{f}$ (p.u.) & 0.05 & 0.05 & 0.05 & $\infty$ & $\infty$ \\
\hline
\end{tabular}

TABLE I

POWER REFERENCE VALUES AND DROOP COEFFICIENTS OF THE VSC-HVDC CONVERTERS

\section{A. Case of an AC event}

In this simulation, the $\mathrm{AC}$ grid 1 is a weak islanded $\mathrm{AC}$ grid (250 MW generation). The power withdrawn from the DC grid by the converter 1 is set at $200 \mathrm{MW}$ (almost $45 \%$ of the total power of the AC grid). At $t=2 \mathrm{~s}$, an additional load of $50 \mathrm{MW}$ is connected, leading to a power imbalance on the AC grid.

Because of the imbalance between load and generation, the frequency of the AC grid 1 decreases. Figure 4 and 5 show respectively the frequency of the $\mathrm{AC}$ grid 1 and the power transiting through the VSC converter when:

- Only the voltage droop of the dual controller of converter 1 is activated (no frequency droop).

- The dual controller is fully activated and the frequencydroop parameter is the original value.

- The dual controller is fully activated and the frequencydroop parameter is the corrected value.

The dashed curve shows a larger frequency decrease since the frequency droop of the VSC converter is not activated and thus no power is being extracted from the DC grid and injected into the $\mathrm{AC}$ grid to stabilize the frequency.

\footnotetext{
${ }^{1}$ The voltage-droop parameter values were computed to achieve a time response of $100 \mathrm{~ms}$, see [9] for more information.
}

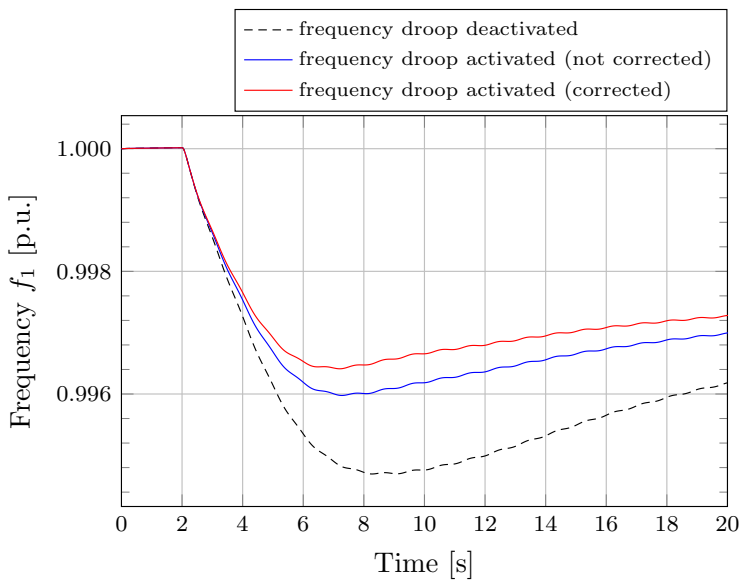

Fig. 4. Frequency of the AC grid 1

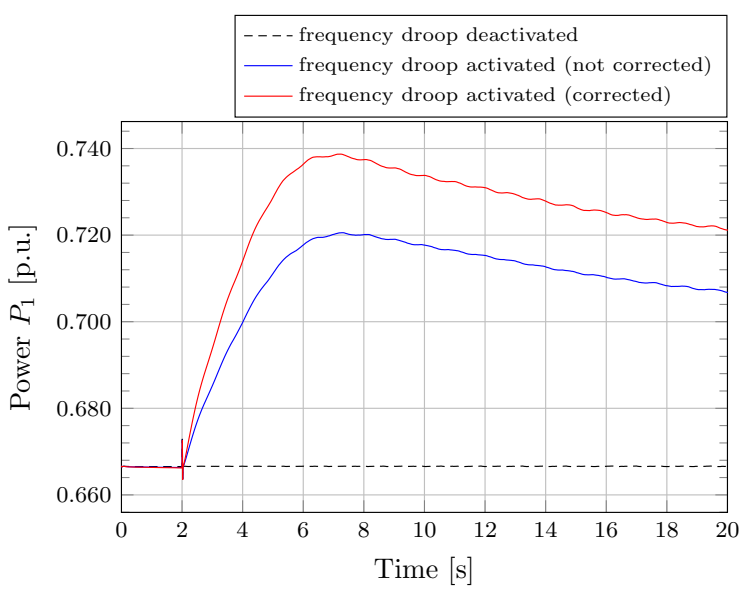

Fig. 5. Power transiting through the VSC-HVDC converter 1 ( 1 p.u. $=300$ MW)

The blue curve corresponds to the case where the frequency droop is enabled but the frequency-droop parameter is the original parameter that has not been corrected. In this case, the disruptive interactions between the two droops prevents the frequency droop from functioning at its full capacity. In fact, the TSO of the AC grid 1 expects a frequency-droop parameter $k_{f_{1}}$ from the VSC converter such that $k_{f_{1}}=\frac{\Delta f_{1}}{\Delta P_{1}}=0.05$ p.u., but according to Figures 4 and 5, the effective frequency-droop parameter is $k_{f_{1}}^{\prime}=\frac{\Delta f_{1}}{\Delta P_{1}}=0.074$ p.u. because of the disruptive interactions between the two droops.

The red curve corresponds to the case where the frequency droop is enabled and the corrected value of the frequencydroop parameter has been implemented so that the frequency droop compensates the disruptive interaction between the droops. The TSO of the AC grid 1 expects an effective frequency-droop parameter $k_{f_{1}}^{\prime}$ from the VSC converter such that $k_{f_{1}}^{\prime}=\frac{\Delta f_{1}}{\Delta P_{1}}=0.05$ p.u. In order to comply with this condition, the corrected frequency-droop parameter $k_{f_{1}}$ 
implemented in the VSC converter is:

$$
k_{f_{1}}=k_{f_{1}}^{\prime}\left(1-\frac{1}{k_{v_{1}} \sum_{j=1}^{3} \frac{1}{k_{v_{j}}}}\right)=\frac{1}{30}
$$

and according to Figures 4 and 5, the effective frequencydroop parameter is actually equal to $k_{f_{1}}^{\prime}=\frac{\Delta f_{1}}{\Delta P_{1}}=0.05$ p.u., despite the disruptive interaction between the voltage and the frequency droops.

\section{B. Case of a DC event}

In this scenario, the VSC-HVDC converter 4 is lost at $t=2 \mathrm{~s}$. Two simulations are run: in the first one, the AC grid 1 is a strong AC grid (20 GW generation), while in the second one the AC grid 1 is a weak AC grid (250 MW generation). The power withdrawn from the DC grid by the converter 1 is the same in both simulations and is set at $200 \mathrm{MW}$.

Figure 6 shows that after the loss of converter 4 originally working as a rectifier, the DC voltage decreases, causing the three converters equipped with a voltage-droop control to modify their power operating point in order to balance the MTDC system and stabilize the DC voltage.

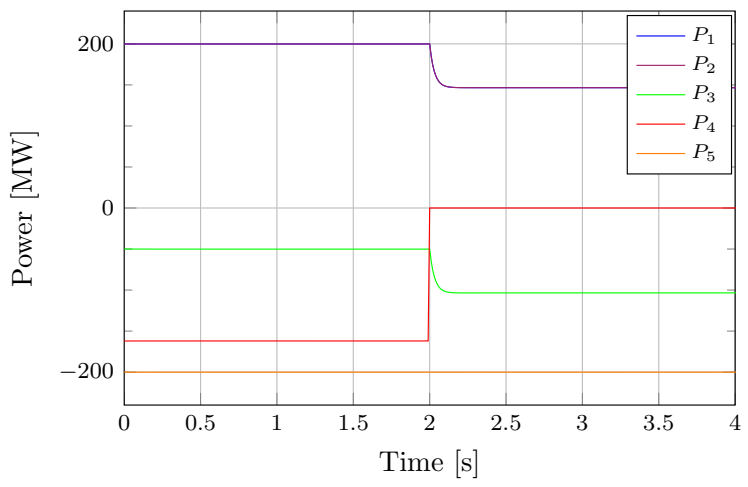

Fig. 6. Power injection/withdrawal of the VSC-HVDC converters before and after the disconnection of converter $4\left(P_{1}\right.$ and $P_{2}$ are superposed in this figure)

Figure 7 shows the frequency of the AC grid 1 and Figure 8 shows the voltage of the DC grid when:

- Only the voltage droop of the dual controller of converter 1 is activated $\left(k_{f_{1}}=\infty\right)$.

- The dual controller is fully activated and the AC grid 1 is a weak AC grid.

- The dual controller is fully activated and the AC grid 1 is a strong $\mathrm{AC}$ grid.

The voltage droop of the converter 1 working as an inverter reduces the amount of power extracted from the DC grid. This creates a power imbalance on the AC grid 1 that results in a frequency decrease which, in turn, initiates the frequency droop of the dual controller. This is the coupling between the voltage droop and the frequency droop. In fact, the power set point variation due to the frequency droop is not equal to zero and partially cancels the power deviation created by the voltage droop. This causes the DC voltage to drop lower when the dual converter is fully activated than when the frequency droop of the dual controller is not activated: the frequency droop hampers the proper functioning of the voltage droop.

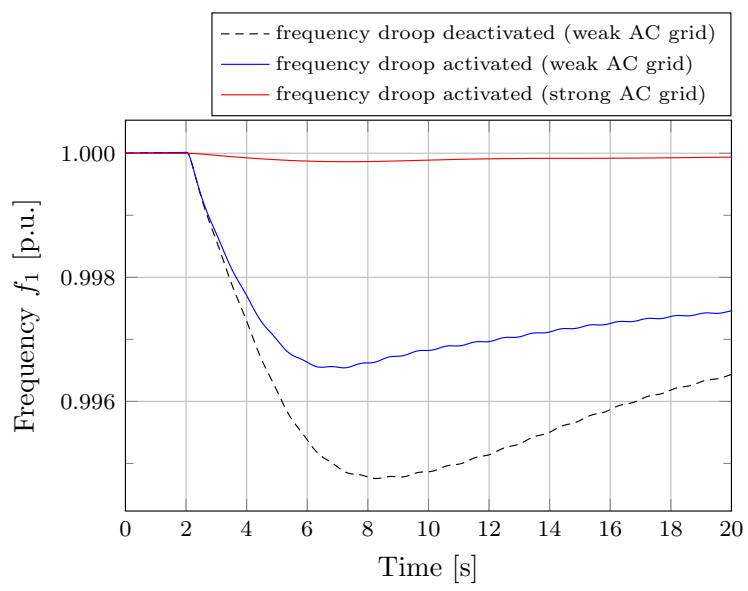

Fig. 7. Frequency of the AC grid 1

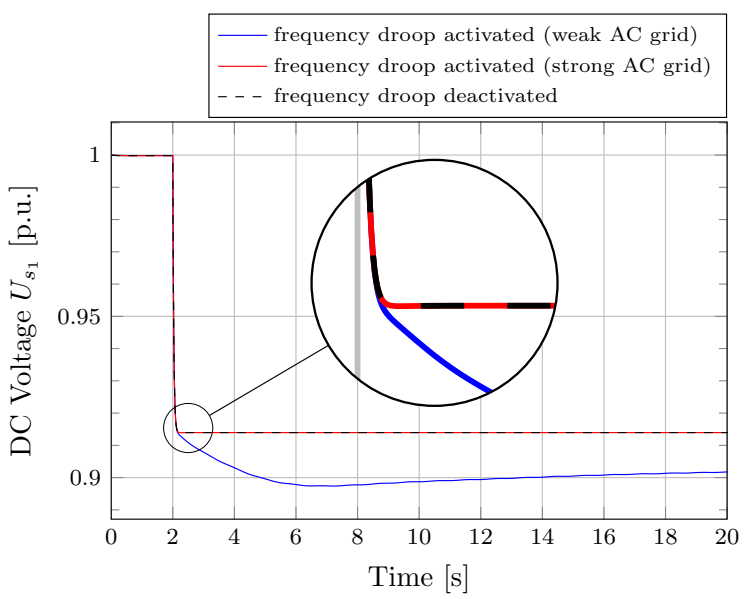

Fig. 8. DC voltage at the converter 1 terminal

In particular, if the $\mathrm{AC}$ grid 1 is a strong $\mathrm{AC}$ grid, the impact of the power imbalance on the frequency is minimal whereas it can be substantial if the AC grid 1 is a weak AC grid. This explains why the interaction between the two droops has little impact on the $\mathrm{DC}$ voltage if the $\mathrm{AC}$ grids are strong. However, if one of the $\mathrm{AC}$ grid participating in the $\mathrm{DC}$ voltage droop is a weak $\mathrm{AC}$ grid, then the disruptive interaction between the voltage droop and the frequency droop can become dangerous for the DC grid because it prevents the voltage droop from working correctly.

It is to be noted that the power set point variation due to the frequency droop reflects the dynamics of the frequency of the AC grid. This means initially the voltage droop is not impacted by the frequency droop until the frequency starts decreasing, as shown in the zoomed-in part of Figure 8.

To better illustrate this point, according to (13), the relation between the DC voltage, the frequency of the $\mathrm{AC}$ grids and the 
power deviation due to the loss of converter 4 can be expressed as:

$$
\Delta u_{s}=\frac{P_{4}-\sum_{j=1}^{3} \frac{1}{k_{f_{j}}} \Delta f_{j}}{\sum_{j=1}^{3} \frac{1}{k_{v_{j}}}}
$$

As shown in Figure 7, the frequency deviation created by the interaction between the droops for large $\mathrm{AC}$ grids is negligible, thus $\Delta f_{2}$ and $\Delta f_{3}$ can be neglected.

If the considered scenario corresponds to the case where the AC grid 1 is also a strong $\mathrm{AC}$ grid, then $\Delta f_{1}$ is negligible as well (in fact $\Delta f_{1}=4.81 \mathrm{E}-5$ p.u. according to Figure 7) and the DC voltage deviation calculated by (15) gives $\Delta u_{s}=0.087$ p.u. (which is also confirmed by Figure 8 ). In this scenario, the DC voltage is not impacted by the disruptive interaction between the two droops, and the MTDC system behaves as if the frequency droop of converter 1 were deactivated.

However, if the considered scenario corresponds to the case where the AC grid 1 is a weak AC grid, then $\Delta f_{1}=2.16 \mathrm{E}-3$ p.u. (according to Figure 7) and the DC voltage deviation calculated by (15) gives $\Delta u_{s}=0.094$ p.u. (Figure 8 shows a final $\Delta u_{s}=0.096$ p.u. This $2 \%$ error is generated by the limits of the simplifying assumption (2)). This shows that using a weak AC grid to participate in the DC voltage regulation of the MTDC system can be dangerous since it leads, in this case, to a $8 \%$ increase in DC voltage variation on the HVDC grid.

\section{CONCLUSiOns}

In an MTDC system, each VSC-HVDC converter connected to an AC grid can be equipped with a DC voltage-droop controller to participate in the DC voltage regulation of the HVDC grid, and with a frequency-droop controller to participate in the onshore grid frequency regulation. However, using both controllers at the same time (also called dual controller) creates a disruptive interaction between the two droops.

Because of this coupling between the voltage droop and the frequency droop, the initial frequency-droop parameter needs to be corrected in order to fulfil the TSO's requirements despite being hampered by the voltage droop. For this purpose, a corrected value of the frequency-droop parameter has been proposed and validated.

On the other hand, the frequency droop must not hamper the functioning of the DC voltage droop during a DC event. It has been shown in this paper that the frequency droop has a limited impact on the DC voltage of an MTDC system as long as the frequency of the AC grids shows very small deviations, which is generally the case for large AC grids. However, if a weak AC grid is connected to the MTDC system, the frequency droop of the converter connected to this weak AC grid can dangerously aggravate any possible DC voltage variation on the MTDC system. This increased voltage variation needs to be taken into account in the choice of the voltage-droop parameters and the design of the DC grid.

\section{REFERENCES}

[1] The European Wind Energy Association, "EWEA annual report 2012," in EWEA Annual Reports, June 2013.

[2] The European Commission, "Renewable energy: Processing towards the 2020 target." Communication from the Commission to the European Parliament and the Council, January 2014.

[3] N. Kirby, L. Xu, M. Luckett, and W. Siepmann, "HVDC transmission for large offshore wind farms," Power Engineering Journal, vol. 16, pp. 135141, June 2002.

[4] T. M. Haileselassie, "Control of multi-terminal VSC-HVDC systems," Master's thesis, Norvegian University of Science and Technology, 2008.

[5] J. Beerten and R. Belmans, "Modeling and control of multi-terminal VSC HVDC systems," Energy Procedia, vol. 24, pp. 123-130, 2012.

[6] P. Rault, X. Guillaud, F. Colas, and S. Nguefeu, "Investigation on interactions between AC and DC grids," in PowerTech, 2013 IEEE Grenoble, pp. 1-6, June 2013.

[7] N. Chaudhuri, R. Majumder, and B. Chaudhuri, "System frequency support through multi-terminal DC (MTDC) grids," Power Systems, IEEE Transactions on, vol. 28 No. 1, pp. 347-356, February 2013.

[8] S. Akkari, M. Petit, J. Dai, and X. Guillaud, "Interaction between the voltage-droop and the frequency-droop control for multi-terminal HVDC systems," in AC and DC Power Transmission. 11th IET International Conference on, Birmingham, February 2015.

[9] P. Rault, Dynamic Modeling and Control of Multi-Terminal HVDC Grids. PhD thesis, Laboratory L2EP, University Lille Nord-de-France, 2014.

\section{APPENDIX}

DC cable specifications:

\begin{tabular}{|c|c|c|c|c|c|c|}
\hline DC line & $\mathbf{1}$ & $\mathbf{2}$ & $\mathbf{3}$ & $\mathbf{4}$ & $\mathbf{5}$ & $\mathbf{6}$ \\
\hline Length $(\mathrm{km})$ & 150 & 150 & 175 & 150 & 125 & 200 \\
\hline
\end{tabular}

DC cable data:

$r=5.347 \mathrm{~m} \Omega / \mathrm{km} \quad l=3.740 \mathrm{mH} / \mathrm{km} \quad c=0.247 \mu \mathrm{F} / \mathrm{km}$

$g=6.207 \mathrm{E}-8 \mathrm{~S} / \mathrm{km}$

AC OHL data:

$R=20 \mathrm{~m} \Omega / \mathrm{km} \quad l=0.853 \mathrm{mH} / \mathrm{km} \quad c=0.0135 \mu \mathrm{F} / \mathrm{km}$

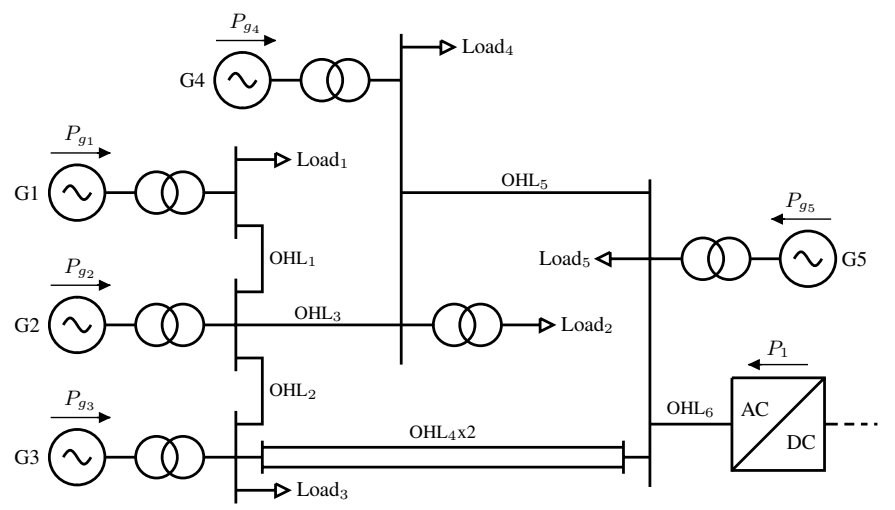

Fig. 9. Simplified diagram of the AC grid 1 